\title{
Envelhecimento humano e velhice: espaços e formas dessa temática dentro dos cursos de Psicologia no estado do Rio Grande do Sul
}

\author{
Patrícia Di Francesco Longo*, Eliane Lucia Colussi*
}

\section{Resumo}

Este trabalho teve como objetivo verificar como está sendo tratado o estudo sobre a velhice e o processo de envelhecimento humano em três cursos de Psicologia de três instituições de ensino superior (IES) localizadas em cidades da região Norte do estado do Rio Grande do Sul. Os estudos sobre envelhecimento humano e velhice tornam-se cada vez mais relevantes, uma vez que, no Brasil, observa-se redução significativa da participação na população com idade até 25 anos e aumento no número de idosos. Buscou-se, também, compreender, com base nas concepções e conceituações relatadas nas entrevistas, como os coordenadores e professores abordam teoricamente a temática nas disciplinas curriculares. A pesquisa teve abordagem qualitativa, e a coleta de dados foi efetuada por meio de entrevista semiestruturada, com o foco principal de compreender os espaços ocupados pela temática dentro dos cursos pesquisados. As entrevistas foram realizadas inicialmente com os coordenadores dos cursos e poste- riormente com professores indicados pela coordenação, totalizando 9 participantes, 3 coordenadores de cursos e 6 professores. A análise de dados abarcou as seguintes fases: pré-análise, exploração do material, tratamento dos dados obtidos e interpretação do conteúdo. Por meio das entrevistas, concluiu-se que o envelhecimento e a velhice são assuntos ainda pouco abordados nos cursos de Psicologia e, quando o são, a perspectiva predominante relaciona a temática diretamente ao adoecimento, à institucionalização da pessoa idosa e à disciplina de desenvolvimento humano.

Palavras-chave: Psicologia. Velhice. EnveIhecimento. Educação superior.

" Psicóloga, graduada pela Universidade Regional e Integrada (URI) - Campus de Erechim. Especialista em Gestão de Pessoas pela Universidade de Passo Fundo (UPF). Mestra em Envelhecimento Humano pela UPF. Endereço para contato: Av. Pedro Pinto de Souza, 181, apto. 901, CEP: 99700-000, Erechim - RS. E-mail: pattylongo@hotmail.com.

** Docente do Programa de Pós-Graduação em Envelhecimento Humano (ppgEH) da UPF. Mestra e Doutora em História pela Pontifícia Universidade Católica do Rio Grande do Sul. E-mail: colussi@upf.br.

$\longrightarrow$ Recebido em setembro de 2012 - Aprovado em outubro de 2012.

$\hookrightarrow$ doi:10.5335/rbceh.2012.033 


\section{Introdução}

A partir da metade do século XXI, o Brasil passou a perceber a inversão da pirâmide etária, o que ocorreu devido a vários fatores, entre os quais, a diminuição da taxa de mortalidade e fecundidade, bem como o aumento de expectativa de vida no país. Essa nova realidade de um país com uma significativa população envelhecida trouxe novos desafios a várias áreas de estudos. Afinal, foi e ainda é preciso preparar as pessoas para lidar com esse novo cenário social. (CARVALHO; RODRÍGUEZ-WONG, 2008).

Pensando nesse panorama, Lebrão (2007) afirma que é necessário que os profissionais de todas as áreas comecem a agir e pensar em formas de proporcionar subsídios para que a população envelhecida se torne mais saudável, ativa e independente por mais tempo. Sendo assim, constata-se a pertinência de analisar o espaço de temáticas em torno da velhice e do envelhecimento humano nos cursos de graduação em Psicologia. A formação dos profissionais preparados para atender as demandas dessa população exigirá tanto reformulações curriculares quanto capacitação do corpo docente, visando à adequação dos cursos às necessidades da sociedade atual.

Nesse sentido, trabalhos publicados por Anita L. Neri, em especial o intitulado "Contribuições da Psicologia ao estudo e à intervenção no campo da velhice", trazem uma panorâmica sobre a situação da formação do psicólogo e a necessidade de incluir nos conteúdos de formação profissional as temáticas relacionadas à velhice, propondo um conjunto de possibilidades para reverter tal quadro. A análise da produção científica sobre a questão confirma que o posicionamento de Anita Neri permanece atual.

Nessa perspectiva, uma parte significativa dos artigos publicados sobre a formação acadêmica dos psicólogos enfatiza críticas relacionadas à inconsistência entre os conteúdos ministrados na maioria dos cursos de Psicologia e a atual realidade e necessidade social do Brasil. Assim, vários estudos acerca dessa formação focalizam, de forma geral, as fragilidades verificadas em relação a determinadas problemáticas contemporâneas, contexto em que a velhice e o envelhecimento aparecem, não raras vezes, de forma indireta.

Junqueira e Kovács, pesquisando alunos finalistas de um curso de graduação em Psicologia com o objetivo de verificar como estavam sendo tratados a morte e o morrer no curso de Psicologia por parte dos professores, verificaram que os graduandos não se sentiam preparados para lidar com a questão e que o tema era abordado com superficialidade durante a formação acadêmica. As autoras também constataram que os psicólogos precisam estar preparados para lidar com as dificuldades que as pessoas sofrem, como o enlutamento, as perdas ou as separações, mencionando, ainda, a importância do acompanhamento psicológico e da atuação junto a idosos, que seria "outro campo de trabalho para os psicólogos, pelas dificuldades psíquicas 
e sociais ligadas ao envelhecimento e pelo fato de estarem, pela idade, mais próximos da morte". (2008, p. 509).

Outro estudo sobre a problemática na formação dos psicólogos no Brasil foi desenvolvido por Portes e Máximo. (2010). Segundo os autores, desde a sua regulamentação, a Psicologia vem acompanhando as diversas transformações sociais, políticas e econômicas do país. Contudo, há a necessidade de uma transformação na formação em Psicologia, a fim de que se torne mais adequada à nova realidade brasileira. $\mathrm{O}$ objetivo do trabalho foi o de identificar as possíveis relações nas matrizes curriculares de um curso de Psicologia de Santa Catarina com as competências e habilidades contidas nas Diretrizes Curriculares Nacionais.

Ao analisar as ementas de disciplinas ministradas no curso, os autores constataram que a disciplina de Psicologia do Desenvolvimento III aborda o desenvolvimento da adultez e do envelhecimento, trazendo a discussão de aspectos biológicos, psicológicos e sociais, todos de grande importância para o planejamento de ações de atenção à saúde em todos os níveis, "considerando que a população idosa em nosso país está aumentando, cada vez mais se fazendo necessário pensar no cuidado em saúde dessa importante parcela da população". (PORTES; MÁXIMO, 2010, p. 153-177).

Nessa mesma perspectiva, a de buscar situar as discussões e os debates sobre a atual situação da área de Psi- cologia e a formação dos profissionais, outro estudo pode ser destacado. Trata-se de pesquisa realizada por Tourinho e Bastos (2010) focalizando a situação da pós-graduação em Psicologia no Brasil. De maneira similar aos estudos sobre a graduação na área, os autores afirmam que a Psicologia precisa enfrentar muitos desafios, entre os quais, a expansão da abrangência geográfica e temática, de modo a vencer assimetrias regionais e desequilíbrios na cobertura das subáreas e temas de pesquisa.

Isso esclarecido, pode-se explicar, em parte, a relativa ausência de temáticas sobre a velhice na Psicologia. Uma das justificavas de tal situação é o fato de que o estudo do envelhecimento humano pela Psicologia é relativamente recente, pois passou a ocorrer a partir do século XX apenas, juntamente com o envelhecimento dos cientistas que haviam desenvolvido as principais teorias sobre a infância e a adolescência. (NERI; JORGE, 2006).

A regulamentação da profissão de Psicólogo ocorreu em 27 de agosto de 1962, através da Lei n. 4.119. De acordo com Mancebo (2004), os profissionais que difundiram as práticas da Psicologia Aplicada foram fundamentais para a regulamentação da profissão. Ainda segundo a autora, no ano de 1962, foram delimitados o currículo mínimo e a duração mínima para os cursos de Psicologia. Já as funções do psicólogo foram determinadas dois anos depois, através do Decreto n. 53.464, de 21 de janeiro de 1964. 
Em 2001, surgiram as Diretrizes Curriculares Nacionais, propondo uma reforma na formação dos profissionais de saúde. Inicialmente, os cursos contemplados foram os de Medicina e Enfermagem e, posteriormente, os demais cursos da área da saúde. Através da Resolução n. 8, de 7 de maio de 2004, foram instituídas as Diretrizes Curriculares Nacionais para os cursos de Psicologia. (BRASIL, 2004).

A partir das Diretrizes Curriculares, ficam estabelecidas, no Parecer do MEC, as competências, habilidades e atitudes necessárias ao profissional psicólogo para facilitar a interação e atuação multiprofissional em benefício dos indivíduos e das comunidades, promovendo a saúde para todos. As competências estabelecidas pelo parecer assinalam a atenção à saúde, a tomada de decisões, a comunicação, a administração, o gerenciamento e a educação permanente. (BRASIL, 2004).

As competências mencionadas no parecer remetem a uma realidade na qual os cursos devem estar sempre se adaptando de acordo com a realidade vivenciada pela sociedade brasileira. Batomé (2006) afirma que, para que isso ocorra, é necessário incentivar o acadêmico dos cursos de Psicologia a responder: "qual a Psicologia de que a população brasileira realmente precisa?". Sendo assim, o graduando seria incentivado a desenvolver as habilidades, atitudes e competências necessárias para lidar com realidades como a do envelhecimento da população brasileira.
Nessa perspectiva, acredita-se ser imprescindível a ampliação de estudos e pesquisas que avaliem a realidade dos projetos pedagógicos e das matrizes curriculares que vêm formando os profissionais da Psicologia, uma vez que esses estudos devem abarcar, também, a área do envelhecimento humano, a partir do modo como os conteúdos, as atividades extracurriculares e os campos de estágio contemplam ou não a complexidade desse processo. Acredita-se que o envelhecimento humano torna-se uma das etapas do desenvolvimento cada vez mais proeminentes, corroborando, desse modo, indicadores populacionais, em referência mundial e nacional, que apontam para um crescimento irreversível da população idosa e aumento na expectativa de vida, em comparação com a população de crianças e jovens.

\section{Método}

O estudo é de abordagem qualitativa, a qual, em termos metodológicos, permite que se responda a questões particulares que, geralmente, não podem ser quantificadas, pois abrangem o universo da subjetividade. Trata-se de tentar explicar os significados, as crenças, os valores, as atitudes, o dito e o não dito, abrangendo um espaço mais profundo dos processos, das relações e dos fenômenos que não são reduzidos a operacionalizações de variáveis. (MINAYO, 2004). Para o estudo em desenvolvimento, parte-se de pesquisa de campo por meio de entrevistas. 
Como instrumento auxiliar de pesquisa, foi utilizado o tópico guia, o qual consiste em um pequeno roteiro ou "lembrete" que serve como orientação inicial para o pesquisador, estabelecendo as principais questões norteadoras a serem abordadas junto ao entrevistado. (BAUER; GASKELL, 2008). O tópico guia, um modelo de entrevista semiestruturada, permite maior liberdade tanto ao pesquisador quanto ao recordador, pois confere maior liberdade a este último, que é respeitado em sua vontade e seus limites.

A população-alvo deste estudo foram cursos de Psicologia de três IES da região norte do estado do Rio Grande do Sul. O critério utilizado para a seleção da amostra foi a relevância dessas IES no âmbito regional, a sua procura por muitos universitários da região e a existência de cursos de Psicologia nessas instituições.

Participaram da pesquisa coordenadores do curso de Psicologia das três IES, designadas como Alpha, Beta e Gama. Cada coordenador foi convidado a indicar, para fazer parte da pesquisa, professores que trabalham com a temática do envelhecimento humano e velhice em seus cursos. Sendo assim, a população foi definida por meio dos critérios da pesquisa qualitativa, em que se deve levar em consideração a capacidade e a potencialidade dos participantes de discorrer sobre o tema proposto. (SCARPARO, 2000).

A pesquisa teve início somente após as IES aceitarem participar da pesquisa e mediante a autorização do Comitê de Ética em Pesquisa da UPF (Parecer n. 544/2011). Antes de serem entrevistados, todos os participantes concordaram em assinar o Termo de Consentimento Livre e Esclarecido, que teve por base a Resolução 196/96 do Conselho Nacional de Saúde, que trata da participação de pessoas na pesquisa e que já havia sido previamente validado pelo Comitê de Ética.

A pesquisa resultante neste artigo teve como ponto de partida a fala dos coordenadores dos cursos selecionados, na medida em que eles ocupam um papel central no desenvolvimento e na execução do projeto pedagógico de cada curso; acrescente-se, ainda, o fato de que, em princípio, cabe-lhes dominar e orientar o desenvolvimento dos conhecimentos globais do curso que coordenam. Em seguida, foram realizadas entrevistas com nove professores dos cursos, registrando-se que este estudo, por ser de caráter qualitativo, não se baseia em critério numérico para garantir representatividade. (MINAYO, 2004).

Inicialmente, a pesquisa contaria com a participação de 1 professor da instituição Alpha, 3 professores da instituição Beta e 4 professores da instituição Gama, os quais haviam sido indicados pelos coordenadores dos cursos por trabalharem com a temática do envelhecimento humano e da velhice. Por meio de convite feito via e-mail e, posteriormente, via telefone, todos os professores das instituições Alpha e Beta mostraram-se interessados em participar da pesquisa. 
Contudo, na instituição Gama, a entrevista foi realizada com apenas dois dos professores indicados, pois, dentre os demais, um alegou não trabalhar com a área do envelhecimento humano e o outro não respondeu às tentativas de contato.

As entrevistas foram realizadas individualmente e focaram a forma e a frequência com que a temática do envelhecimento humano e da velhice é abordada nos cursos de Psicologia. Respeitando a disponibilidade de cada participante, a aplicação das entrevistas teve início com os coordenadores dos três cursos, para posteriormente serem realizadas com os professores, os quais são identificados neste artigo como P1, P2, P3, P4, P5 e P6, sendo $\mathrm{P} 1$ docente da instituição Alpha; P2, P4 e P5, da instituição Beta; e P3 e P6, da instituição Gama.

As entrevistas, cuja duração foi de no mínimo trinta minutos e de no máximo uma hora, ocorreram nos locais sugeridos pelos professores, na maioria dos casos, seu ambiente de trabalho. Todas foram gravadas para posteriormente serem transcritas e analisadas. A análise e a interpretação dos dados envolveram as quatro fases propostas por Minayo (2004) para a análise de conteúdos: pré-análise, exploração do material, tratamento dos dados obtidos e sua interpretação.

\section{Resultado e discussão}

O objetivo do estudo centrou-se em verificar como estão sendo abordados os conteúdos sobre a velhice e o processo de envelhecimento humano em três cursos de Psicologia de três instituições de ensino superior (IES). Também, buscou-se compreender, com base nas concepções e conceituações relatadas nas entrevistas, como os coordenadores e professores abordam teoricamente a temática nas disciplinas curriculares. Nesse sentido, a pesquisa respondeu parcialmente aos objetivos inicialmente propostos. Como será visto a seguir, os participantes da pesquisa e as instituições às quais estão vinculados apresentaram conceitos e características inerentes às especificidades de formação e origem institucional.

$\mathrm{O}$ primeiro aspecto analisado no estudo foi o histórico das instituições que participaram da pesquisa, uma vez que os cursos de Psicologia da amostra foram criados em contextos históricos diferentes: o primeiro tem 34 anos; o segundo, 11 anos; e o terceiro, 7 anos. À luz dessa análise inicial, constatou-se que o tempo de vida de cada curso influencia diretamente na construção de determinado modelo de formação profissional.

Percebeu-se, igualmente, que o número de disciplinas envolvendo a temática do envelhecimento humano e da velhice é pequeno, uma vez que os cursos têm duração média de cinco anos, sendo normalmente ministradas entre seis e sete disciplinas por semestre. Os cursos de Psicologia das instituições Alpha e 
Beta têm apenas uma disciplina relacionada à temática do envelhecimento e da velhice, enquanto o curso Gama possui quatro disciplinas acerca do assunto. A justificativa para esse fato parece vir da própria coordenação dos cursos, que tende a enfatizar uma área da Psicologia em detrimento de outra(s). Contudo, não se pode deixar de mencionar que o curso da instituição Gama é coordenado por um professor que teve a dissertação de mestrado focada nessa temática, o que pode ter influenciado diretamente no fato de este ser o curso com maior ênfase nas questões relacionadas ao envelhecimento humano e à velhice.

A disciplina que aparece como denominador comum para o trato da temática é a de Desenvolvimento Humano. De acordo com Bee (1997), sendo trabalhado somente nessa disciplina, o envelhecimento tende a ser visto de forma bastante técnica e compreendido apenas como mais uma fase do ciclo vital, que abrange aspectos que vão do físico-motor ao afetivo-emocional. Dito de outro modo, acaba-se mostrando o envelhecimento como uma fase distante da vida dos acadêmicos, cuja maioria tem em torno de 20,30, 40 anos de idade. Além disso, essa fase acaba sendo tratada apenas como um momento de perdas.

A fala dos coordenadores dos cursos pontua exatamente o que foi acima mencionado: "[...] quando a gente fala de Psicologia do Desenvolvimento, uma delas está focada [...] no envelhecimento humano [...]" - coordenador do curso
Alpha; “[...] Dentro de algumas disciplinas, principalmente na disciplina de Desenvolvimento, $[. .$.$] que é a Psicologia$ do Desenvolvimento [...]" - coordenador do curso Beta; e "[...] uma disciplina que nós chamamos de Psicologia do Desenvolvimento III, voltada diretamente para o estudo do envelhecimento humano" coordenador do curso Gama.

Os coordenadores dos cursos demonstram, em suas falas, compreender a importância de abordar o envelhecimento humano e a velhice nos cursos de Psicologia. No entanto, fica evidente a dificuldade de encontrar um caminho para trabalhar essas questões com os graduandos, principalmente no que se refere a linhas teóricas, o que também é ratificado na fala de $\mathrm{P} 1$ :

[...] as teorias psicológicas, e aí, eu acho que eu já te dou um dado, as teorias psicológicas, isso eu acho que a Neri traz muito bem, que são poucas perto das outras áreas, então, o que acaba acontecendo? Tem as teorias psicológicas, mas como elas não são muito vastas, acaba então que os psicólogos, também por não ter tantas teorias para trabalhar em cima da questão do envelhecimento humano, acabam que talvez também (são vários fatores), talvez não tenham tanto interesse.

P2 corrobora a fala de P1, ao alegar que:

A Psicologia do Desenvolvimento mesmo, a Psicologia do Desenvolvimento, ela nasce com o estudo das crianças propriamente ditas, há um aprofundamento enorme do estudo do Desenvolvimento Infantil e um aprofundamento bem pequeno, se dá para dizer aprofundamento, no estudo do envelhecimento. 
Essas falas fundamentam a necessidade de a Psicologia pesquisar mais sobre o envelhecimento humano e a velhice propriamente dita. Afinal, as correntes e perspectivas teóricas do desenvolvimento humano têm focado muito mais a fase da infância e da adolescência do que a adultez e a velhice. (NERI; JORGE, 2006).

Num sentido mais amplo, Portes e Máximo afirmam que a história da Psicologia é recente no Brasil. Ela tem menos de 50 anos de história até o momento, "construindo muitos dos seus referenciais teóricos, pautados numa atuação e numa formação voltada para a prática clínica individual" (2010, p. 155-177). Tal histórico reflete diretamente na constituição dos currículos, pois se entende que esses são produto das finalidades de um grupo de pessoas, de uma opção de conteúdos considerados válidos.

Os professores foram mais enfáticos do que os coordenadores, ao mencionarem os assuntos abordados dentro da temática nos cursos de Psicologia. De acordo com a sua fala, pode-se perceber que são eles que dão o tom do que e de que forma trabalhar as questões relacionadas ao envelhecimento humano e à velhice, como evidenciam as frases abaixo:

Eu dou um panorama mais amplo da questão demográfica, cultural, o que a aposentadoria significou para o envelhecimento humano, e daí eu também trabalho nesta parte a questão do envelhecimento biológico, bem específico assim [...]. Trabalho as possíveis intervenções em diferentes locais, mas prin- cipalmente nas casas de longa permanência, o que o psicólogo pode fazer e o que ele pode promover, porque não precisa só ele fazer, ele pode chamar outros profissionais... (P1).

Esse professor demonstra abordar muito mais as questões voltadas à institucionalização do idoso, ou seja, além das questões relacionadas ao desenvolvimento, trabalha com os alunos o envelhecimento vinculado à Psicologia Social. Sendo assim, insere esse idoso na sociedade, buscando compreender suas relações sociais. (RODRIGUES, 2000).

P2 também utiliza essa abordagem teórica para trabalhar com os alunos a temática do envelhecimento e da velhice, como se pode perceber na seguinte fala: "[...] Acabo puxando um pouco a brasa para os estudos em Representação Social, e aí eu dou exemplos de estudos em Representação Social em envelhecimento até para levar um pouco o que eu estudei e tal".

P3, no entanto, enfoca o envelhecimento humano e a velhice na perspectiva da Psicologia Organizacional e do Trabalho, o que é evidenciado em sua fala: “[...] na própria área de Psicologia Organizacional, tenho trabalhado esta questão de projeto de preparação para a aposentadoria, e daí a gente dá uma pincelada [...]".

As abordagens em que o envelhecimento humano e a velhice podem ser trabalhados são vastas. Uma das possibilidades é olhá-los de uma perspectiva de testagens, utilizando materiais e métodos psicológicos para compreender melhor essa população. P4 trabalha nessa perspectiva e afirma: 
Para você ter uma ideia, eu já trabalho há alguns anos com a disciplina de Psicodiagnóstico, mas eu acho que... deixa eu ver de quantos anos para cá, de uns três ou quatro anos para cá, foi que eu introduzi a avaliação psicológica do idoso, considerando o envelhecimento [...] eu estou trabalhando é muito mais assim, na perspectiva de avaliação psicológica nessa faixa etária.

Essa fala reforça a ideia de que o estudo da velhice e do envelhecimento humano é ainda bastante recente dentro da Psicologia.

Ao contrário de $\mathrm{P} 4$, que trabalha a temática voltada para questões mais práticas, P5 a aborda de forma mais teórica "[...] estou tentando passar subsídios teóricos para os alunos sobre o envelhecimento e a possibilidade de intervenção com pessoas da terceira idade". A fala demonstra que esse professor não se sente suficientemente seguro para trabalhar as questões relacionadas à velhice e ao envelhecimento humano, bem como para realizar intervenções com essa população.

P6, por sua vez, sugere utilizar uma abordagem mais ampla com os alunos, $o$ que é demonstrado em sua fala:

Pego tudo, desde os aspectos psicológicos, os aspectos sociais, biológicos, né, psicossociais [...]. Toda a adultez madura, o que é o adulto maduro e depois o envelhecimento, que até a maior parte da disciplina é ligada a isso. Toda a questão do que é a adultez velha, do que é envelhecimento, os processos que acontecem no envelhecimento, as questões que eu abordo, como eu falei, o psicológico, aspectos sociais, a sexualidade, a questão de internação em casas geriátricas ou asilos. A questão familiar, a questão que surgiu do cuidado, a questão do casamento longevo...
O curto espaço de tempo reservado pelos cursos para as questões do envelhecimento justifica o fato de cada docente ter de selecionar os aspectos que considera mais relevantes para trabalhar com os acadêmicos. Sendo assim, a fala de P6 é a mais enigmática dentre as obtidas, pois é o único que afirma trabalhar todos os aspectos que envolvem a temática. Contudo, devido à amplitude e ao pouco espaço de tempo, não se sabe qual é o aprofundamento dado à questão mencionada por esse professor.

É importante mencionar que os professores entrevistados ministram diversas disciplinas e, contrariando a fala dos coordenadores de cursos, que pontuavam que o envelhecimento humano e a velhice eram trabalhados quase exclusivamente dentro da disciplina de Desenvolvimento Humano, esses docentes conseguiram encontrar meios de abordar as questões relacionadas à velhice e ao envelhecimento em suas aulas. No entanto, isso somente é possível graças a um desejo interno desses profissionais de trabalhar com a temática.

Observa-se a dificuldade do diálogo interdisciplinar no que se refere à necessidade percebida pelos participantes da pesquisa quanto à forma de abordagem dos conteúdos. Para Motta e Aguiar, a Gerontologia

é intrinsecamente interdisciplinar, pois o processo de envelhecimento permeia todos os aspectos da vida. Incorpora conteúdos científicos e técnicos de vários campos, nos quais se destacam a Biologia, a Psicologia e as Ciências Sociais. A Gerontologia opera 
a criação de novas estruturas conceituais que, ao romperem com as estruturas disciplinares de origem, são recombinadas e sintetizadas de forma a configurar uma nova totalidade. (2007, p. 367).

Ao longo da pesquisa, foram entrevistados 6 professores, dos quais apenas 2 trabalhavam diretamente com a disciplina de Desenvolvimento Humano (P1 e P6), sendo eles um professor da instituição Alpha e um da instituição Gama. Um dos questionamentos que fica é o porquê de o professor titular da cadeira de desenvolvimento humano da instituição Beta não ter sido indicado pelo coordenador do curso para participar da pesquisa. Apesar de não se ter uma resposta fechada para essa pergunta, pode-se inferir que isso ocorra pelo fato de a temática, algumas vezes, estar sendo mais enfatizada por outros professores do que pelos próprios docentes das disciplinas de Desenvolvimento Humano.

Motta e Aguiar (2007) dão suporte aos professores que estão trabalhando questões relacionadas ao envelhecimento humano e à velhice em suas disciplinas, salientando que o envelhecimento faz parte do ciclo de vida e que as competências relacionadas à atenção ao idoso estão contempladas indiretamente nas diretrizes curriculares. Logo, como mencionado anteriormente, esse assunto deveria ser abordado na maioria das disciplinas ao longo do curso, não deixando tal incumbência somente às de Desenvolvimento Humano.
Espera-se que este trabalho proporcione uma reflexão e uma possível atitude de mudança no trabalho dos docentes, na elaboração dos seus planos de ensino, na recomendação das referências bibliográficas, abrangendo as considerações das Diretrizes Curriculares Nacionais e as ponderações aqui presentes. Aos discentes, deseja-se que este trabalho proporcione uma reflexão acerca do comprometimento como um sujeito ativo na sua própria formação e preocupado com as reais necessidades sociais da comunidade. (PORTES; MÁXIMO, 2010).

\section{Conclusão}

Por meio da pesquisa, evidenciou-se a dificuldade que os cursos de Psicologia enfrentam em trabalhar as quatro principais ênfases de maneira unificada. Sendo assim, pode-se afirmar que os cursos pesquisados não contemplam uma visão real e generalista sobre o assunto em questão.

Outro ponto que chama a atenção é o fato de nenhuma das IES estudadas possuir programas para trabalhar com a preparação para o envelhecimento, o que se percebe pela ausência da temática no âmbito da Psicologia Escolar em todos os cursos pesquisados.

Nos cursos de Psicologia investigados, o envelhecimento humano e a velhice são inseridos na disciplina de Desenvolvimento Humano e, na maioria das vezes, dividem a cadeira com a temática da adultez (adulto jovem, adulto e adulto velho). Considerando a abrangência da 
temática e a sua complexidade, o espaço que lhe é destinado dentro dos cursos permanece bastante restrito.

Os cursos das instituições Beta e Gama aparentam trabalhar mais com essa temática do que o curso da Alpha. Na instituição Beta, verifica-se que o trabalho com a questão do envelhecimento humano é decorrente de iniciativa dos próprios professores, que, na maioria dos casos, demonstram interesse individual pela temática. No entanto, o termo "velho" ou "idoso" ainda é mascarado por estereótipos, como os relacionados à terceira idade.

Somente na instituição Gama, a temática parece estar sendo mais abordada, visto que já faz parte de quatro cadeiras no decorrer do curso. Nessa instituição, a questão parece ser tratada com a devida importância; afinal, ao fazer uma comparação com os cursos de Alfa e Beta, percebe-se que, nestes últimos, a temática é trabalhada mais especificamente em uma cadeira ao longo da graduação e em outras somente quando existe a iniciativa dos docentes.

Acredita-se que estudos dessa natureza possam ser realizados em outras instituições de ensino que oferecem cursos de Psicologia, para que se tenha um diagnóstico mais amplo em relação ao espaço que o processo de envelhecimento humano ocupa nos projetos pedagógicos e às abordagens que vêm sendo priorizadas a respeito desses conteúdos, principalmente porque 2012 foi o ano do cinquentenário da Psicologia como profissão. Seria, portanto, um momento propício para questionar as práticas dos psicólogos e rever a formação acadêmica dos futuros profissionais da área. A partir de outras pesquisas, será possível investigar se o aparente descaso dos psicólogos com a temática da velhice e o pouco espaço oferecido para o tema dentro dos cursos ocorrem somente na região do Rio Grande do Sul, ou se isso é comum a outros estados brasileiros.

\section{Human agingand old age: spaces} and waysof this subject with in the Psychology courses in Rio Grande do Sul State

\section{Abstract}

The present article has analyzed the spaces occupied by content related to human aging and old age in three Psychology courses of higher education institutions located in the northern region of Rio Grande do Sul. Studies on human aging and old age become increasingly relevant since population indicators worldwide in Brazil is observed a significant reduction from participation of population aged up to 25 years and increase the number of elderly. The study aimed to understand, from the concepts and conceptualizations reported in the interviews, how the coordinators and professors approach this topic in the curriculum subjects. In search of answers a qualitative research was conducted, data collection was conducted through semistructured interviews, focused on understanding the space occupied by the theme in the courses surveyed, performed first with courses coordinators and later with professors indicated by the coordination. Totalizing nine participants, three course coordinators and six professors. The data analysis covered the following phases: pre- 
-analysis, material exploration, processing of data and interpretation of content. The foundings showed that aging and old age are subjects scantly covered in Psychology courses and, when they are, the predominant prospect relates the theme directly to illness, to the institutionalization of the elderly and the discipline of human development

Keywords: Psychology. Elderly. Aging. Higher Education.

\section{Referências}

BATOMÉ, S. P. Comportamentos profissionais do Psicólogo em um sistema de contingências para a sua aprendizagem. Revista Brasileira de Análise do Comportamento, Brasília, v. 2, n. 2, p. 171-191, 2006.

BAUER, M.; GASKELL, G. Pesquisa qualitativa com texto, imagem e som: um manual prático. Petrópolis - RJ: Vozes, 2008.

BEE, H. O ciclo vital. Porto Alegre: Artmed, 1997.

BRASIL. Ministério da Educação. Resolução n. 8, de 7 de maio de 2004. Diretrizes Curriculares Nacionais para os Cursos de Graduação em Psicologia. Diário Oficial da União. Brasília, 2004.

CARVALHO, J. A.; RODRÍGUEZ-WONG, L. L. A transição da estrutura etária da população brasileira na primeira metade do século XXI. Cadernos de Saúde Pública, Rio de Janeiro, v. 24, n. 3, p. 597-605, 2008.

JUNQUEIRA, M. H. R.; KOVÁCS, M. J. Alunos de Psicologia e a educação para a morte. Psicologia Ciência e Profissão, Brasília, v. 28, n. 3, p. 506-519, 2008.

LEBRÃO, M. L. O envelhecimento no Brasil: aspectos da transição demográfica e epidemiológica. Saúde Coletiva, São Paulo, v. 4, n. 17 , p. 135-40, 2007.
MANCEBO, D. Formação em Psicologia: gênese e primeiros desenvolvimentos. Mnemosine, Rio de Janeiro, v. 1, p. 53-72, 2004.

MINAYO, M.C. (Org.). Pesquisa social: teoria, método e criatividade. Petrópolis, RJ: Vozes, 2004.

MOTTA, L. B.; AGUIAR, A. C. Novas competências profissionais em saúde e o envelhecimento populacional brasileiro: integridade, interdisciplinaridade e intersetorialidade. Ciência \& Saúde Coletiva, Rio de Janeiro, v. 12 , n. 2, p. 363-372, 2007.

NERI, A. L. Contribuições da Psicologia ao estudo e à intervenção no campo da velhice. Revista Brasileira de Ciências do Envelhecimento Humano, Passo Fundo, v. 1, n. 1, p. $69-80,2004$.

NERI, A. A. L.; JORGE, M. D. Atitudes e conhecimentos em relação à velhice em estudantes de graduação em educação e em saúde: subsídios ao planejamento curricular. Estudos de Psicologia, Campinas, v. 23, n. 2, p. 127-137, 2006.

PORTES, J. R. M.; MÁXIMO, C. E. Formação do psicólogo para atuar no SUS: possíveis encontros e desencontros entre diretrizes curriculares nacionais e as matrizes curriculares de um curso de psicologia. Barbaroi, Santa Cruz do Sul, n. 33, p. 153-177, 2010.

RODRIGUES, A. Psicologia social. Petrópolis, RJ: Vozes, 2000.

SCARPARO, H. Psicologia e pesquisa: perspectivas metodológicas. Porto Alegre: Sulinas, 2000.

TOURINHO, E. Z.; BASTOS, V. B. Desafios da pós-graduação em Psicologia no Brasil. Psicologia Reflexão e Crítica, Porto Alegre, v. 23, p. 35-46, 2010. 